\title{
REFERENCE
}

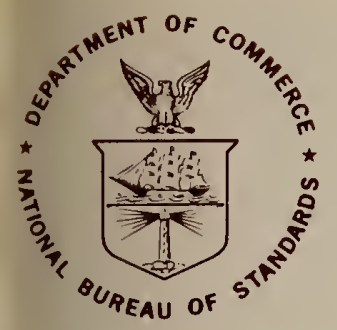

NBS TECHNICAL NOTE $\mathbf{8 0 1}$

U.S. DEPARTMENT OF COMMERCE / National Bureau of Standards

\section{Research Considerations in Computer Networking to Expand Resource Sharing}

$-Q C-$
100
.45753
$n o .801$
1974




\section{NATIONAL BUREAU OF STANDARDS}

The National Bureau of Standards ${ }^{1}$ was established by an act of Congress March 3, 1901. The Bureau's overall goal is to strengthen and advance the Nation's science and technology and facilitate their effective application for public benefit. To this end, the Bureau conducts research and provides: (1) a basis for the Nation's physical measurement system, (2) scientific and technological services for industry and government. (3) a technical basis for equity in trade. and (4) technical services to promote public safety. The Bureau consists of the Institute for Basic Standards, the Institute for Materials Research, the Institute for Applied Technology, the Institute for Computer Sciences and Technology, and the Office for Information Programs.

THE INSTITUTE FOR BASIC STANDARDS provides the central basis within the United States of a complete and consistent system of physical measurement; coordinates that system with measurement systems of other nations; and furnishes essential services leading to accurate and uniform physical measurements throughout the Nation's scientific community, industry, and commerce. The Institute consists of a Center for Radiation Research, an Office of Measurement Services and the following divisions:

Applied Mathematics - Electricity - Mechanics - Heat - Optical Physics - Nuclear Sciences $^{2}$ - Applied Radiation ${ }^{2}$ - Quantum Electronics ${ }^{3}$ - Electromagnetics ${ }^{3}$ - Time and Frequency ${ }^{3}$ - Laboratory Astrophysics ${ }^{3}$ - Cryogenics *.

THE INSTITUTE FOR MATERIALS RESEARCH conducts materials research leading to improved methods of measurement, standards, and data on the properties of well-characterized materials needed by industry, commerce, educational institutions, and Government; provides advisory and research services to other Government agencies; and develops, produces, and distributes standard reference materials. The Institute consists of the Office of Standard Reference Materials and the following divisions:

Analytical Chemistry - Polymers - Metallurgy - Inorganic Materials - Reactor

Radiation - Physical Chemistry.

THE INSTITUTE FOR APPLIED TECHNOLOGY provides technical services to promote the use of available technology and to facilitate technological innovation in industry and Government; cooperates with public and private organizations leading to the development of technological standards (including mandatory safety standards), codes and methods of test; and provides technical advice and services to Government agencies upon request. The Institute consists of a Center for Building Technology and the following divisions and offices:

Engineering and Product Standards - Weights and Measures - Invention and Innovation - Product Evaluation Technology - Electronic Technology - Technical Analysis

- Measurement Engineering - Structures, Materials, and Life Safety - Building

Environment " - Technical Evaluation and Application " - Fire Technology.

THE INSTITUTE FOR COMPUTER SCIENCES AND TECHNOLOGY conducts research and provides technical services designed to aid Government agencies in improving cost effectiveness in the conduct of their programs through the selection, acquisition, and effective utilization of automatic data processing equipment; and serves as the principal focus within the executive branch for the development of Federal standards for automatic data processing equipment, techniques, and computer languages. The Institute consists of the following divisions:

Computer Services - Systems and Software - Computer Systems Engineering - Information Technology.

THE OFFICE FOR INFORMATION PROGRAMS promotes optimum dissemination and accessibility of scientific information generated within NBS and other agencies of the Federal Government; promotes the development of the National Standard Reference Data System and a system of information analysis centers dealing with the broader aspects of the National Measurement System; provides appropriate services to ensure that the NBS staff has optimum accessibility to the scientific information of the world. The Office consists of the following organizational units:

Office of Standard Reference Data - Office of Information Activities - Office of Technical Publications - Library - Office of International Relations.

1 Headquarters and Laboratories at Gaithersburg, Maryland, unless otherwise noted; mailing address Washington, D.C. 20234.

${ }^{2}$ Part of the Center for Radiation Research.

3 Located at Boulder, Colorado 80302.

4 Part of the Center for Building Technology. 


\section{Research Considerations in Computer Networking to Expand Resource Sharing}

Dennis W. Fife

Systems and Software Division

Institute for Computer Sciences and Technology

U.S. National Bureau of Standards

Washington, D.C. 20234

t. Technical note no. 801

Sponsored by:

National Science Foundation

18 th and G Street, N.W.

Washington, D. C. 20550

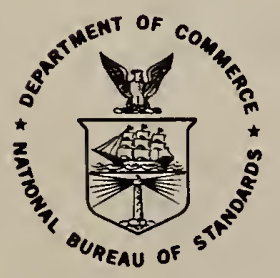

U.S. DEPARTMENT OF COMMERCE, Frederick B. Dent, Secrefary

NATIONAL BUREAU OF STANDARDS, Richard W. Roberts, Director

Issued June 1974 


\section{Library of Congress Catalog Card Number: 74-600089}

\section{National Bureau of Standards Technical Note 801}

Nat. Bur. Stand. (U.S.), Tech. Note 801, 24 pages (June 1974)

CODEN: NBTNAE 


\section{FOREWORD}

The author is grateful for review assistance from Al Neumann, Jim Dei Rossi, and particularly Mike Keplinger, who suggested reference [12].

This report is one of a series completed by NBS with support of the National Science Foundation, Office of Computing Activities, Grant AG-350. A complete listing follows:

1. Primary Issues in User Needs

D. W. Fife

Chapter 10 in Networks for Research and Education:

Sharing of Computer and Information Resources

Nationwide

MIT Press, Cambridge, Mass.

Expected Publication in 1974.

2. Some Technical Considerations for Improved Service

to Computer Users

T. N. Pyke, Jr.

COMPCON, 1973

Seventh Annual IEEE Computer Society International Conference

3. Computer Networking Technology - A State-of--the-Art Review

R. P. Blanc and T. N. Pyke, Jr.

COMPUTER Magazine, August 1973.

Computer Society of the IEEE

4. Review of Network Management Problems and Issues

A. J. Neumann

NBS Technical Note 795

October 1973

5. Annotated Bibliography of the Literature on

Resource Sharing Computer Networks

R. P. Blanc, I. W. Cotton, T. N. Pyke, Jr., and

S. W. Watkins

NBS Special Publication 384

September 1973

6. Network Management Survey

I. W. Cotton

NBS Technical Note 805

February 1974 
7. User Procedures Standardization for Network Access A. J. Neumann

NBS Technical Note 799

October 1973

8. Review of Computer Networking Technology

R. P. Blanc

NBS Technical Note 804

January 1974

9. Microeconomics and the Market for Computer Services

I. W. Cotton

Submitted to Computing Surveys

10. Cost Analyses for Computer Communications

R. P. Blanc

NBS Technical Note

May 1974

11. Network User Information Support

A. J. Neumann

NBS Technical Note 802

December 1973

12. Computer Networking: Approaches to Quality Service Assurance

R. B. Stillman

NBS Technical Note 800

January 1974

13. A Guide to Networking Terminology

A. J. Neumann

NBS Technical Note 803

March 1974

14. Research Considerations in Computer Networking to Expand Resource Sharing

D. W. Fife

NBS Technical Note 801

April 1974

15. Network Management for Expanded Resource Sharing

D. W. Fife

Facts and Futures

Proc. EDUCOM Fall Conference 1973 
16. Networking Challenges: The Users Viewpoint

R. P. Blanc

Facts and Futures

Proc. EDUCOM Fall Conference 1973

17. Availability and Usability of Computer Communication Networks

R. P. Blanc

Proc. Seventh International Conference on

System Sciences,

January 1974 
1. BACKGROUTD $\cdot \cdot \cdot \cdot \cdot \cdot \cdot \cdot \cdot \cdot \cdot \cdot^{\circ}$ Page

1. BACKGROUND .................... . 1

2. NETWORK MANAGEMENT FUNCTIONS .............. 2

3. PROGRESSIVE STAGES OF RESOURCE SHARING . . . . . . . . . 4

4. NETWORK MANAGEMENT EVALUATION ........... 5

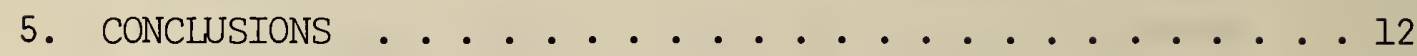

6. FUTURE RESEARCH AND EXPERTMENTATION . . . . . . . . 13 


\section{Dennis W. Fife}

Computer networking technology is adequately developed now to support research and experimentation to expand computing resource sharing. Whether progress will be made depends upon organizational initiative among multiple institutions, to pool personnel and capital so as to effectively address the major issues in management approach, support, and software design that limit the feasible interdependence of computing operations. The organizational requirements are partially revealed by examining progressive stages of resource sharing in onganizational and operational terms rather than such technical aspects as load sharing or program sharing that have been introduced in the past. Five stages are identified, ranging from simply establishing multiple service access to the advanced stage where multiple institutions organize for joint development of new resources. A preliminary evaluation framework for new management arrangements results when these stages are mapped against the four functional levels inherent in computer network management. Future needs for networking experimentation and research are briefly described, and other NBS technical results are identified in context.

Keywords: Computer network management; computer networking research; management evaluation; resource sharing.

\section{BACKGROUND}

Remote access computing via data communications facilities has grown tremendously over the past decade, and is now established as one of the important future growth areas for the computing business. The more recent connotation -- resource sharing -- has been fostered by Government-funded projects emphasizing either computing service distribution and user support, e.g. NSF regional networking projects [1], or innovative, communications facilities, e.g. ARPANET. The future availability of suitable communications capabilities for resource-sharing is very promising. A variety of techniques and systems have emerged as operationally successful [2], and conmercial development activity is high on the part of common carriers, specialized carriers, value-added network enterprises, and the newly-announced ventures to commercially exploit the ARPANET technology.

On the other hand, the future character of resource sharing is quite uncertain regarding long-term cooperative commitments among autonomous institutions and expanded support for research computing capabilities that are not commercially appealing. Current experience suggests 
that significant cost savings will not develop without lange-scale service aggregation and reorganization that normally is achievable only under strong central management. Also, remote access tends to aggravate the users' operational problems unless there are well-planned, additional steps in documentation, training, etc. Such observations illustrate that important issues and research problems exist in broad areas of network management, remote user support, and associated software design and management practices. The new NSF research initiative in networking $[3,4]$ addresses these unresolved problems in research studies and . through experimental network operations taking on a supra-regional or national orientation.

The early regional networks were dominated by one major institution with sharable computing resources and expertise, which naturally provided a central management structure. One highly significant distinction in nationally-oriented experiments will be the collaboration of several major institutions, each with appreciable computing capability to offer. Also, financial investments from several major institutions may well be needed to supplement research grants in initiating an experimental network. These factors imply that future networking experiments must involve high-level management initiative and careful negotiation to form an acceptable management organization. A leading concern will be to preserve the autonomy and investments of the participants, while giving active leadership to reach the operational goals.

A carefully prepared network management plan appears then to be one of the most important elements of a networking experiment. It will help to estimate the potential success of the experiment, and also guide other experimenters toward pertinent criteria and commitments. To encourage innovation and to accomodate the varying needs of participants, it is not advisable to delineate one management structure as uniformly desirable. Even so, there is a range of management issues, taking on different interpretations according to the extent of resource sharing intended, that should be addressed in a proposed solution. The organization and characterization of these issues as they might be considered in a management plan is a principal goal of this report. The report thereby gives a preliminary evaluation mechanism for network management, inasmuch as it aids an initial review of completeness and pertinence, prior to a detailed evaluation of the specific considerations of an experiment.

\section{NETWORK MANAGEMENT FUNCTIONS}

In an environment of resource sharing among multiple institutions, network management must encompass four directive functions. These are identified by reviewing the management organizations of existing network operations [5] and the traditional functions of complex service organizations. Neumann [6] defines them in relation to altemative organizational hierarchies, which perhaps would be the most prevalent implementation form, although not the only one possible. The basic motivation 
and objective for each function aid in understanding our subsequent expression of management issues.

Policy Direction. Participating institutions will require continuing review and directive authority to ensure that the goals and policies in a networking project are consistent with their objectives, philosophies, and requirements. A common approach is to establish a policy conmittee or board of trustees composed of high-level officials (agency director, dean, or provost) who represent institutional responsibility for the project. Policymakers would seek to preserve control over the means to satisfy their institution's computing requirements, and to optimize the computing capability available for their requirements, considering required costs and investment.

\section{Executive/Technical Direction. Translation of general goals and} policy into specific accomplishments will require effective leadership to formulate specific objectives and approaches, to assign or distribute resources, and to monitor progress against required performance. Ideally, executive direction would be assigned to one individual on behalf of all participants, but co-equal directors and committees have been accepted compromises. Having overall responsibility for realization of the technical facilities and objectives, the executive director is motivated to obtain sufficient resources and support for development and operation, and to meet participant requirements expeditiously within the available support.

Operations Direction. The technical complexity and workload usually involved in the daily provision of remote access service demands a skilled and responsible individual to manage the operations and maintenance staff. Although each computer center will have an operations manager, coordination problems and the interaction with data communications operations may require a "network" operations manager or coordinator responsible for overall service. The principal objective would be to maintain high reliability and service effectiveness according to established performance criteria and within assigned resource capacity. But operations should also help identify unfulfilled requirements and service limitations, for future development or resolution.

User Assistance/Marketing Direction. From both an administrative and technical standpoint, remote users require a basic amount of assistance in gaining access to a service and some continuing aid in solving operational problems. As a very limited and easily consumed resource, the available time and skills of consultants, aids, and training specialists must be judiciously assigned to scheduled and unscheduled activities. In commercial services, the responsibility is usually assigned to an individual manager. In academia and Government that approach has also been employed, as well as less formal means such as volunteer coordinators. The objective of the "marketing" group is to develop user awareness and dexterity regarding basic operating procedures and available services, within their capacity. They may also stimulate 
recognition of new resource sharing approaches that better serve user needs.

\section{PROGRESSIVE STAGES OF RESOURCE SHARTNG}

When the scope or type of resource sharing being undertaken is recognized, the above definitions can be extended to delineate more specific concerns for each function. However, the past identified types of resource sharing -- e.g. load sharing, data sharing, program sharing -- are not particularly helpful since they relate more to software than to management considerations. Five new categories are proposed here to describe evolutionary stages in resource sharing development, beginning from the now prevalent posture of institutional self-sufficiency in computing. Each is a necessary stage preceding its successor, although it also is apparent that a given network could be implemented to pass directly through one or more stages. As a first level classification, it requires judgement to place a given network within an appropriate category, by deciding the relative importance of different aspects of its operation.

Mutual Service Access. This initial phase of resource sharing only establishes possible access by individual users to multiple remote computer systems. All participating institutions thus permit the cooperating external services to compete with their local computer centers to meet their users' needs -- but perhaps not in free competition. Policy modifications and management action may frequently be necessary to revise outside procurement rules and funding procedures. The user would deal directly with each available service regarding his needs. There would be minimal management interaction with users on computer centers.

Mutual Support. This phase develops when each organization establishes formal assistance mechanisms regarding accounts, documents, training, and usage problems, to aid its members in using all available computer systems. Some mutual support in financial transactions, e.g. billing and collection, would be appropriate also. The independence of computer centers would be preserved.

Operations coordination. This phase requires each organization to arrange basic operational or management procedures and criteria in agreement with other centers, to provide more. uniformity and ease of user access to various systems. Common accounting criteria, protocol elements, and control/commuications factors (e.g. prompting characters) would be typical considerations. The aggregate service and resources offered by each computer center would be of its choice, but demand levels could change with easier access and use. Explicit methods for load sharing and balancing might be introduced at this stage, but each computer center would be expected to have independent discretion in setting service priorities with respect to the market. 
Service Alignment. This stage arises when organizations recognize unique services that each can provide, and then mutually contract to provide complementing resources to meet the major needs of their total market.* Computer centers thus will specialize in certain types of service, and organizations will become mutually dependent in satisfying their composite needs. Such dependence would be significant financially, for an institution may require an assured market to support its investment in offered services.

Joint Resource Ownership. This stage evolves when organizations mutually invest capital and personnel resources to develop a new computing resource for their common use. An institution would thereby acquire a vested interest in another organization's computer center. As a result, participants become most strongly conmitted to resource sharing through joint ownership, and the operating independence of joint computing centers is more constrained than in other forms of resource sharing.

\section{NETWORK MANAGEMENT EVALUATION}

In order to conceive an effective network management organization, the responsible parties must first recognize the tangible products of management activity that are pertinent to their intended scope of resource sharing. Then acceptable approaches for each activity can be negotiated, and organizational responsibilities and procedures defined. Network management of course includes traditional activities such as personnel selection, work scheduling, budgeting, etc. but these do not need particular discussion unless the resource sharing goals warrant a unique innovative approach.

The above stages of resource sharing generally indicate progressive goals, extending from the now prevailing case of institutional selfsufficiency in computing. The earlier definition of management directive functions gives the other dimension needed in order to identify needed management results in specific terms useful to initiate management planning or to evaluate a management plan. A self-explanatory description of the major products necessary has been carefully created in Table I to $V$. For ease of comparison and interpretation, each result is keyed as either: D - development, i.e. principally a result of research and planning; A - action, denoting the major continuing work activity; or $\mathrm{R}$ - review, involving mostly monitoring and evaluation for input to other functions or action. In framing each table, the accomplishments of preceding stages are assumed and not repeated, consistent with the envisioned progression of the stages. For brevity, a rationale for each requirement will not be given, but may be inferred from the following discussion of the evolution of each management function.

"Potential "restraint of trade" questions may have to be resolved, see [12]. 
Policy Direction. At the initiation of resource sharing, policy direction likely stems from previously designated officials of each participating organization, acting with occasional discussion and coordination. Their basic problem, which is undiminished perhaps until the stage of Joint Ownership, is to ensure a rational, stable market for computing services, favoring or at least protecting their own onganization and adequately responding to its members' needs. Policy direction must establish basic controls and criteria to this end, and probably evolve or at least approve the fundamental concepts and practices in such areas as finance or institutional roles and prerogatives. The complexity and intensity of the effort in the Operations coordination and Services Alignment stages may require a formal board (e.g. secretariat, regular meetings, published minutes), while in the Joint Ownership stage a distinguished board of trustees is implied.

Executive/Technical Direction. At the initiation of resource sharing, executive direction may be a quite dispersed function emanating from middle level managers concerned with enforcing policy direction and providing associated guidance to computing users. However, leadership is essential at the outset, to effectively present resource sharing needs for policy resolution. The leadership responsibility continues to grow in subsequent stages, transcending or assimilating individual organizational concerns, and contributing the initiative and direction for creating essential tools and practices. The need for a strong executive function is apparent for Operations coordination and its successors, where difficult issues may need forceful resolution. The Joint Ownership stage, as a corporate activity, calls for an individual executive with abilities as a fund-raiser and financial manager.

Operations Direction. Initially, each computing center contributes independently to realize the overall operations direction function. As Mutual Support is introduced, regular information exchange and coordination become necessary. At the Operations Coordination stage, formal procedures and perhaps a Network Operations Director seem advisable because of the active technical coordination involved, especially if a load sharing concept is adopted. As resource sharing evolves, further, emphasis on high quality, easily accessible service grows correspondingly. Operations direction should be competitive and innovative in these aspects, emerging in the Services Alignment and Joint Ownership stages as a strong proponent of new resource offerings and developments.

User Aid/Marketing Direction. Initially, each computing center provides independent assistance to its customers, local or remote, attempting to meet their essential needs within competitive economic limits and to extend the acceptability of its service in the remote market. From the Mutual Support phase onward, the burden of user assistance and market development is assumed to fall on a local "marketing" group attached to each participating organization. (This focuses on non-commercial networking where widespread aggressive service marketing would be unappreciated.) Very close interchange becomes 
critical between the local support groups and the operations staff of the individual computing centers, so that the user aides are themselves properly trained and have the technical sources for problem solving. A role for a network-wide assistance coordinator perhaps emerges. By the time resource sharing reaches the Joint Ownership Stage, user assistance practice should be well developed, so that joint investment, of itself, would introduce no fundamental changes.

Table I. Management Results for Mutual Service Access

\section{Policy Direction}

*(D): Acceptable needs criteria for external services.

(A): Market entry agreements with external services.

$(R)$ : Usage factors affecting computing economy, fiscal balance.

\section{Executive/Technical Direction}

(D): Revised procurement and funding practice for computing services (by individual institutions).

(A): Usage and needs reporting for policy review.

$(R)$ : Selection factors in using available services.

Operations Direction

(D): Competitive service improvements, e.g. reliability.

(A): Service scheduling and reliable operation for remote users' needs.

(R): Problems on remote equipment or in service acceptance.

\section{User Aid/Marketing Direction}

(D): Technical guidelines on innovative service applications.

(A): Economical assistance practice for remote user group.

$(R)$ : Service effectiveness and acceptance.

${ }^{*} \mathrm{D}=$ Development, $\mathrm{A}=$ Action, $\mathrm{R}=$ Review, see Section 4, page 5 . 
Table II. Management Results for Mutual Support

Policy Direction

(D): Goals for user satisfaction with support and services.

(A): Joint support and funding agreements among services.

(R): Support factors affecting service economy and extemal demand.

Executive/Technical Direction

(D): Budgeting and priority guidance for support activities.

(A): Reporting and evaluation of service and support effectiveness.

$(R)$ : Technical support innovations and costs.

Operations Direction

(D): Competitive improvements in user support.

(A): Training, documentation, and assistance to remote support group.

(R): Quality and competitive balance of remote support activities.

User Aid/Marketing Direction

(D): Automated assistance requirements to facilitate user support.

(A): Mutual assistance practice, especially in problem diagnosis.

$(R)$ : User satisfaction with support concepts and techniques. 
Table III. Management Results for Operations Coordination

Policy Direction

(D): Acceptability and priority of operations standards, for economic feasibility and user satisfaction.

(A): Agreements for coordination, including financial considerations for added overhead and development.

(R): Criteria for load sharing pertinent to networking objectives and revenue requirements.

\section{Executive/Technical Direction}

(D): Formulation and assessment of uniform operations plans.

(A): Standardization of pertinent technical elements, billing and accounting practice, and workload measurement and reporting practice.

(R): Service demand trends and cost-benefit factors in uniform operations.

\section{Operations Direction}

(D): Competitive improvements in operational simplicity; design and evaluation of candidate system modifications.

(A): Implementation of uniform interfaces, controls, and user aids; load sharing and balancing.

(R): Workload and overhead factors in uniform operations.

User Aid/Marketing Direction

(D): User needs and recommendations for operational uniformity.

(A): Uniform assistance practice and facilities.

(R): User satisfaction with service accessibility. 
Policy Direction

(D): Selection considerations for primary resource suppliers (e.g. langest user, least cost service, offered investment, etc.) and for alternative resource suppliers, to achieve quality service, demand distribution, competitive innovation.

(A): Marketing agreements and service contracts among participants including considerations of pricing, royalties, and revenue sharing.

$(R)$ : Criteria for supply-demand allocation and pricing, for user satisfaction and financial stability.

Executive/Technical Direction

(D): Formulation and assessment of service allocation concepts; market research and economic analysis.

(A): Standardization of pricing and financial practices, and extension of uniform measurement and reporting practice.

(R): Supplier capabilities and service quality.

Operations Direction

(D): Competitive improvement in resources and service; formulation and proposal of resource offerings.

(A): Implementation of selected resources and services; measurements of workload and service quality; load distribution.

(R): Service economics, viability and synergy of resources.

User Aid/Marketing Direction

(D): Complementing relationships of quality services that best meet user needs.

(A): Technical aid in experimental uses of distributed resources.

$(R)$ : User satisfaction with diversified resources. 
Table V. Management Results for Joint Resource Ownership

Policy Direction

(D): Criteria for investment requirements or limitations on participants.

(A): Selection among resource investment candidates; execution of ownership, operating contracts.

(R): Financial and development progress on network services.

Executive/Technical Direction

(D): Technical and financial evaluation of candidate resource projects.

(A): Distribution and monitoring of joint development resources (capital, personnel, etc.).

$(R)$ : Competitive development approaches and additional funding sources or opportunities.

Operations Direction

(D): Formulation and proposal of new resource development projects.

(A): Development and operation of assigned resource capabilities.

$(R)$ : Potential investment and market support for proposed resources.

User Aid/Marketing Direction

(D): Needs analysis toward new resource definition. 
This report primarily addresses networking participants who have computing resources but are motivated to make other complementing resources available to their user population. Cost-sharing arrangements, e.g. TUCC [7], where outside services are a compatible expansion of the already offered resource, may fit the stages defined here, but they do not raise the substantive issues in mutual support, operations coordination, or services alignment. Most resource sharing networks today exhibit the characteristics of the Mutual Support phase. Only in partial respects have succeeding stages been explored, which is understandable in view of the outstanding technical and management problems involved. For example, Operations coordination is a difficult challenge from the aspect of log-on and basic control sequences [8], unless compatible computer systems are purposely selected. In a similar vein, Services Alignment is critically dependent on effective service quality control which remains a fundamental problem in software irrespective of networking [9].

The relevance of the evaluation schema presented here may be briefly examined in three management cases that are emerging in networking. These are:

a) wholesale-retail operations, e.g. [10];

b) user support centers, e.g. networking information centers, or "automated resource sharing" services;

c) trading coalitions, perhaps operating by analogy with international trade procedures.

The wholesale-retail concept is a specific onganizational form that initially relates to mutual support requirements, but which may be applied in succeeding phases of resource sharing as defined here. Grobstein and Uhlig identify wholesalers as major computer centers; their management exercises a substantial part of Operations Direction, in our terms. Retailers may be simply personnel groups performing the user aid/ marketing function at each participating organization. Or, given some management prerogatives and a computer capability for automating access and interface functions, retailers may participate significantly in Operations Direction as well as User Aid/Marketing Direction. For example, a retailer may distribute the user load among wholesalers, may implement a uniform interface language, or may offer a specialized resource such as a measurement facility. A suggested division of responsibilities among wholesalers, retailers, and the higher levels of network management can be readily checked against Tables I to V. This would identify omitted responsibilities, and assist in comelating the assigned responsibilities with overall resource sharing goals, to judge the completeness and feasibility of a management plan.

The management of specialized resource centers oriented to user support, such as a network information center, is not uniquely treated 
in the preceding, but would have to be considered as it fits in the overall management plan. If the resource is nearly indispensable to effective network usage, the management issues underlying Operations Coordination and Services Alignment are raised. One would expect the overall management plan to address questions of alternate supply, service evaluation, and pricing. In particular, if the center is developed by an entrepreneur rather than as a jointly owned facility, the organizational responsibilities should be examined for effective Policy and Technical Direction.

Trading coalitions modeled after intermational trade [11] are being discussed but none are operating yet. If "free trade" is envisioned, the likely minimal operational and financial alignments would put such networks in the Operations Coordination phase. However, if market specialities or privileged trade agreements also emerge, then Services Alignment is implied. The international trade analogy may lead to specific solutions for such issues in Table IV as market entry conditions, revenue sharing, supply-demand allocation.

The evaluation approach above thus seems broadly applicable to networking in qualitative terms. The limitations are obvious, for much needs to be done in quantitative evaluation of management concepts and techniques. Hopefully, the significance and complexity of network management issues has become apparent, so that network management planning will be a prominent aspect of experimental networking in the future.

\section{FUTURE RESEARCH AND EXPERTMENTATION}

The foregoing analysis and other related NBS studies highlight the following research areas as most important in a foundation for expanded resouce sharing. Detailed recommendations and additional suggestions are developed in the referenced reports. Although some issues may best be undertaken as individual research projects, cooperative research tasks integrated with an experimental network operation are appealing because the realistic constraints and tradeoffs so introduced may lead to more practical solutions. Indeed, substantive experiments based on careful prior planning of management concepts and their operational evaluation would be an ideal approach for developing model solutions in network management.

Market Research for Service Packaging [6, 13]. Significant problems exist in identifying applications-oriented software, data bases, and services that would best serve distinguishable user groups, e.g. in such technical detail as [19-21]. Expected usage or demand projections are rarely available on specific packages or data bases with respect to disciplines and types of users. Such data would visibly assist computer centers in developing related packages and data bases that comprise a relatively complete, distinct service for an identifiable 
user group. Estimates of the economic potential of candidate service packages would be important guidance also. The competitive timesharing business has demonstrated that applications-distinct services have greater success potential than those based only on low cost computing power. The evolution of distinctive service packages thus seems a key factor for expanding resource sharing.

Economic Analyses of Networking [14]. Systematic study is needed of the overall cost of various computing services through networking, and of the potential effect on computing revenues of competitive networking operations. Economic impacts are a continuing concern in the evolution of resource sharing as portrayed here. Even the development of a basic forecasting methodology, validated through a few realistic cases, would be extremely valuable as a tool for computer center managers to individually assess their economic fortunes in the fluid environment of networking.

Computer Communications Guidelines [2, 14-16]. Many papers have been published analyzing communications tariffs and cost trade-offs in simple data communications arrangements. More detailed analyses are desirable for hardware and software performance and cost factors, to provide guidelines for utilizing available technologies. Although several basic technologies have become established, the field is very active and emerging capabilities such as comnercial packet switching and common carrier digital networks could have an important impact on costs and performance. Computing-oriented network planners, especially in senior positions, would benefit from tutorial aids, e.g. [16], and engineering analyses that guide the configuring of experimental networks. One useful result would be a catalog of interfacing requirements (hardware and software) of existing networks, and of "off-the-shelf" hardware and software for low-cost access arrangements among dispersed locations.

Information Requirements in Networking [17]. Two major factors create special concern for satisfying the information needs of network users. They are: the physical separation between resource centers and users, which inhibits conventional interchange; and, the increased technical complexity involved in a wider variety of services from differing systems. Research on innovative communications forms, e.g. teleconferencing, would be desirable, focusing on their contribution to effective resource sharing applications and the attendant costs. Documentation concepts and standards (types of documents, content, format, media), including a widely acceptable taxonomy and descriptive standard for network services, would be appropriate development and research subjects. The use of a network as a primary tool, manifest in searchable data bases on available services, user application problems, etc., would be a natural theme in this area.

Service Quality Assurance [8, 9, 18]. The quality, dependability, and accessibility of network services must clearly be high if users are to accept growing dependence on them. The quality of software 
and the performance of systems remain problematical however because of a lack of accepted, pertinent criteria and of readily applied measurement and evaluation techniques. Of course, partial results are emerging from current development or standardization in certain areas such as mathematical software, compilers for standard languages, and data communications. An overall effort is needed to integrate such results and to identify other performance criteria, giving full coverage to the major network components, i.e., user terminals, communications support network, and host computer services. Measurement and testing techniques should be developed for system-wide application by network and service center managers, and also for individual users to apply in problem diagnosis and applications or service evaluation. New approaches and mechanisms for user feedback to system operators on problems encountered could prove very valuable in organizing dispersed user experience as part of overall testing methodology and system maintenance. 
1. F. W. Weingarten, et. al., "A.Study of Regional Computer Networks", University of Iowa, September, 1972.

2. R. P. Blanc and T. N. Pyke, Jr., "Computer Networking Technology A State of the Art Review", Computer, IEEE Computer Society, August, 1973.

3. D. D. Aufenkamp, "NSF Activities Related to a National Science Computer Network", Computer Comininications: Impacts and Implications, Proceedings of First International Conference on Computer Communications, Washington, D.C., October, 1972.

4. M. Greenberger, et. al. (Editors), Networks for Research and Education: Sharing of Computer and Information Resources NationWIde, MIT Press, Expected publication in 1974.

5. I. W. Cotton, "Network Management Survey", NBS Technical Note 805, February 1974.

6. A. J. Neumann, "Review of Network Management Problems and Issues", NBS Technical Note 795, October 1973.

7. L. H. Williams, "A Functioning Computer Network for Higher Education in North Carolina", Proc. FJCC, 1972, 899-904.

8. A. J. Neumann, "User Procedures Standardization for Network Access", NBS Technical Note 799, October 1973.

9. R. Stillman, "Computer Networking: Approaches to Qualitv Service Assurance" NBS Technical Note 800, January 1974.

10. D. L. Grobstein and R. P. Uhlig, "A Wholesale Retail Concept for Computer Network Management", Proc. FJCC, 1972, 889-898.

11. S. V. Berg, "Networks and Economics: An Application of International Trade Theory", Networks and Disciplines, EDUCOM, 1973, 25-37.

12. D. I. Baker, "Access to Large Computer Systems", Computer Communications: Impacts and Implications, Proceedings of First International Computer Communications Conference, 1972, 431-433.

13. D. Fife, "Primary Issues in User Needs", Networks for Research and Education: Sharing of Computer and Information Resources Nationwide, MIT Press, Expected publication in 1974.

14. R. P. Blanc, "Cost Analyses for Computer Communications", NBS Report in preparation, Expected pubłication May 1974. 
15. R. P. Blanc, "Review of Computer Networking Technology", NBS Technical Note 804, January 1974.

16. A. J. Neumann, "A Guide to Networking Terminology", NBS Technical Note 803, March 1974.

17. A. J. Neumann, "Network User Information Support", NBS Technical Note 802, December 1973.

18. T. N. Pyke, Jr., "Some Technical Considerations for Improved Service to Computer Users", Proc. COMPCON 1973, IEEE Computer Society.

19. B. Marron, et. al., "A Study of Six University-Based Information Systems", NBS Technical Note 781, June. 1973.

20. D. Fife, et al., "A Technical Index to Interactive Information Systems", NBS Technical Note 819, March 1974.

21. B. Marron, et. al., "A Mechanized Information Services Catalog" NBS Technical Note 814, February 1974. 


1. PUBLICATION OR REPORT NO.
NBS TN -801

4. TITLE AND SUBTITLE

RESEARCH CONSIDERATIONS IN COMPUTER NETWORKING TO EXPAND RESOURCE SHARTNG

2. Gov't Accession
No.

2. Gov't Accession
No.

3. Recipient's Accession No.
5. Publication Date

June 1974

6. Performing Organization Code

7. AUTHOR(S)

Dennis W. Fife

9. PERF ORMING ORGANIZATION NAME AND ADDRESS

NATIONAL BUREAU OF STANDARDS

DEPARTMENT OF COMMERCE

WASHINGTON, D.C. 20234

8. Performing Organization

10. Project/Task/Work Unit No.

$640-2415$

11. Contract/Grant No.

12. Sponsoring Organization Name and Address

Same as No. 9

13. Type of Report \& Period Covered

Final

14. Sponsoring Agency Code

15. SUPPLEMENT ARY NOTES

Library of Congress Catalog Card Number: 74-600089

16. ABSTRACT ( 200 -word or less factual summary of most significant information. If document includes a significant bibliography or literature survey, mention it here.)

Computer networking technology is adequately developed now to support research and experimentation to expand computing resource sharing. Whether progress will be made depends upon organizational initiative among multiple institutions, to pool personnel and capital so as to effectively address the major issues in management approach, support and software design that limit the feasible interdependence of computing operations. The organizational requirements are partially revealed by examining progressive stages of resource sharing in organizational and operational terms rather than such technical aspects as load sharing or program sharing that have been introduced in the past. Five stages are identified, ranging from simply establishing multiple service access to the advanced stage where multiple institutions organize for joint development of new resources. A preliminary evaluation framework for new management arrangements results when these stages are mapped against the four functional levels inherent in computer network management. Future needs for networking experimentation and research are briefly described, and other NBS technical results are identified in context.

17. KEY WO RDS (Alphabetical order, separated by semicolons) Computer network management; computer networking research; management evaluation; resource sharing.

X Unlimited

For Official Distribution. Do Not Release to NTIS

E Order From Sup. of Doc., U.S. Government Printing Office Washington, D.C. 20402, SD Cat. No. C13 $46: 801$

Order From National Technical Information Service (NTIS) Springfield, Virginia 22I 51

\begin{tabular}{|l|c|}
\hline $\begin{array}{l}\text { 19. SECURITY CLASS } \\
\text { (THIS REPURT) }\end{array}$ & $\begin{array}{c}\text { 21. NO. OF PAGES } \\
\text { UNCL ASSIFIED }\end{array}$ \\
\hline $\begin{array}{l}\text { 20. SECURITY CLASS } \\
\text { (THIS PAGE) }\end{array}$ & $\begin{array}{c}\text { 22. Price } \\
60 \text { cents } \\
\text { UNCLASSIFIED }\end{array}$ \\
\hline
\end{tabular}


PERIODICALS

JOURNAL OF RESEARCH reports National Bureau of Standards research and development in physics, mathematics, and chemistry. Comprehensive scientific papers give complete details of the work, including laboratory data, experimental procedures, and theoretical and mathematical analyses. Illustrated with photographs, drawings, and charts. Includes listings of other NBS papers as issued.

Published in two sections, available separately:

\section{- Physics and Chemistry (Section A)}

Papers of interest primarily to scientists working in these fields. This section covers a broad range of physical and chemical research, with major emphasis on standards of physical measurement, fundamental constants, and properties of matter. Issued six times a year. Annual subscription: Domestic, $\$ 17.00$; Foreign, $\$ 21.25$.

\section{- Mathematical Sciences (Section B)}

Studies and compilations designed mainly for the mathematician and theoretical physicist. Topics in mathematical statistics, theory of experiment design, numerical analysis, theoretical physics and chemistry, logical design and programming of computers and computer systems. Short numerical tables. Issued quarterly. Annual subscription: Domestic, $\$ 9.00$; Foreign, $\$ 11.25$.

\section{DIMENSIONS, NBS}

The best single source of information concerning the Bureau's measurement, research, developmental, cooperative, and publication activities, this monthly publication is designed for the layman and also for the industry-oriented individual whose daily work involves intimate contact with science and technology - for engineers, chemists, physicists, research managers, product-development managers, and company executives. Annual subscription: Domestic, \$6.50; Foreign, $\$ 8.25$.

\section{RONPERIODICALS}

Applied Mathematics Series. Mathematical tables, manuals, and studies.

Building Science Series. Research results, test methods, and performance criteria of building materials, components, systems, and structures.

Handbooks. Recommended codes of engineering and industrial practice (including safety codes) developed in cooperation with interested industries, professional organizations, and regulatory bodies.

Special Publications. Proceedings of NBS conferences, bibliographies, annual reports, wall charts, pamphlets, etc.

Monographs. Major contributions to the technical literature on various subjects related to the Bureau's scientific and technical activities.

National Standard Reference Data Series. NSRDS provides quantitative data on the physical and chemical properties of materials, compiled from the world's literature and critically evaluated.

Product Standards. Provide requirements for sizes, types, quality, and methods for testing various industrial products. These standards are developed cooperatively with interested Government and industry groups and provide the basis for common understanding of product characteristics for both buyers and sellers. Their use is voluntary.

Technical Notes. This series consists of communications and reports (covering both other-agency and NBS-sponsored work) of limited or transitory interest.

Federal Information Processing Standards Publications. This series is the official publication within the Federal Government for information on standards adopted and promulgated under the Public Law 89-306, and Bureau of the Budget Circular A-86 entitled, Standardization of Data Elements and Codes in Data Systems.

Consumer Information Series. Practical information, based on NBS research and experience, covering areas of interest to the consumer. Easily understandable language and illustrations provide useful background knowledge for shopping in today's technological marketplace.

\section{BIBLIOGRAPHIC SUBSCRIPTION SERVICES}

The following current-awareness and literature-survey bibliographies are issued periodically by the Bureau:

Cryogenic Data Center Current Awareness Service (Publications and Reports of Interest in Cryogenics). A literature survey issued weekly. Annual subscription: Domestic, $\$ 20.00$; foreign, $\$ 25.00$.

Liquefied Natural Gas. A literature survey issued quarterly. Annual subscription: $\$ 20.00$.

Superconducting Devices and Materials. A literature survey issued quarterly. Annual subscription: $\$ 2 C .00$. Send subscription orders and remittances for the preceding bibliographic services to the U.S. Department of Commerce, National Technical Information Service, Springfield, Va. 22151.

Electromagnetic Metrology Current Awareness Service (Abstracts of Selected Articles on Measurement Techniques and Standards of Electromagnetic Quantities from D-C to Millimeter-Wave Frequencies). Issued monthly. Annual subscription: $\$ 100.00$ (Special rates for multi-subscriptions). Send subscription order and remittance to the Electromagnetic Metrology Information Center, Electromagnetics Division, National Bureau of Standards, Boulder, Colo. 80302.

Order NBS publications (except Bibliographic Subscription Services) from: Superintendent of Documents, Government Printing Office, Washington, D.C. 20402. 
